\title{
Extension of the Storage Life of Plums (Prunus salicina) Using Controlled Atmosphere Shipping
}

\author{
L. Maré and M. Huysamer \\ Department of Horticultural Sciences \\ University of Stellenbosch, Private Bag X1 \\ Matieland, 7602 \\ South Africa \\ M.C. Dodd \\ Alacer Aer Technologies, PO Box 60140 \\ Table View, 7439 \\ South Africa \\ A.B. Truter and A.T. Kemp \\ Transfresh Africa, Howard Place \\ Pinelands, 6740 \\ South Africa \\ D.M. Holcroft \\ Dole Fresh Vegetables \\ PO Box 1759, Salinas, CA93902 \\ USA
}

Keywords: Japanese plums, dual temperature, colour, firmness, respiration, ethylene

\begin{abstract}
South Africa is an important supplier of stone fruit to the northern hemisphere in the months of November to March. The voyage by sea to the main markets in the UK and Continental Europe necessitates production of cultivars that are able to maintain an acceptable eating quality for a period of at least four weeks from the time of harvest. Four Japanese plum (Prunus salicina) cultivars were examined with the view to extend their storage life under regular atmosphere (RA) conditions at $-0.5^{\circ} \mathrm{C}$ following either RA or controlled atmosphere (CA) shipping, using either the commercial dual temperature $\left(-0.5^{\circ} \mathrm{C}, 7.5^{\circ} \mathrm{C},-0.5^{\circ} \mathrm{C}\right)$ or a single high temperature $\left(7.5^{\circ} \mathrm{C}\right)$ regime. The cultivars included the locally bred 'Sapphire', 'Songold' and 'Laetitia' as well as 'Angeleno' which is well known in plum producing countries internationally.
\end{abstract}

Storage life of all four cultivars could be extended for an additional two to three weeks under RA conditions at $-0.5^{\circ} \mathrm{C}$ without adverse effects on quality, provided that $\mathrm{CA}$ was applied during the shipping phase, either under the dual or single high temperature regimes. Fruit firmness was best retained under CA (dual temperature) conditions. These fruit also showed the lowest respiration rates, ethylene production rates and internal ethylene content. Skin colour development was better under single high than under dual temperature conditions, and also better under RA than CA shipping.

\section{INTRODUCTION}

The South African plum industry has exported an average of approximately 6 million cartons $(5.25 \mathrm{~kg})$ of Japanese plums annually over the past 10 years (Anon, 2003). The main markets are in Continental Europe (61\% of the total volume), United Kingdom (27\%), Middle East (6\%), Far East (4\%), Indian Ocean Islands (1\%), and the balance to Africa, Canada and Russia. The majority of the cultivars are derived from a local breeding program that focuses on storage ability, as the fruit requires a postharvest storage life of minimally four to five weeks for commercial handling, distribution and marketing. 
The fruit is generally shipped under regular atmosphere (RA) conditions, using reefer containers or conventional reefer vessels. Whereas the shipping of plums internationally is often conducted at a single low temperature of $-0.5^{\circ} \mathrm{C}$, the South African industry makes extensive use of a so-called dual temperature shipping regime, which is a type of intermittent warming. This technology has been adopted to reduce the incidence of certain internal disorders like gel breakdown and internal browning, associated with extended exposure to low, non-freezing temperatures (Taylor, 1996).

The dual temperature regime typically involves fruit being harvested, then sorted, graded, packed and stored at $-0.5^{\circ} \mathrm{C}$ during accumulation for a vessel. Average fruit age at the time of boarding the vessel is about 10 days (from harvest). Two days after departure of the vessel, the delivery air temperature (DAT) is raised to $7.5^{\circ} \mathrm{C}$ for a period of approximately 5-9 days, depending on the cultivar and fruit maturity. Thereafter the DAT is lowered again to $-0.5^{\circ} \mathrm{C}$ until discharge from the vessel. Typical voyage duration to Europe is approximately 16 days, and further distribution occurs at $-0.5^{\circ} \mathrm{C}$, with fruit sometimes being ripened at a higher temperature prior to sale.

The objectives of this research were to attempt to extend the post-shipping storage and distribution life (under RA conditions) of four important plum cultivars by using controlled atmosphere shipping under either a dual temperature regime or a single, high shipping temperature of $7.5^{\circ} \mathrm{C}$. The hypothesis was therefore that CA shipping under either dual temperatures or a single high temperature would extend the post-shipping storage life under RA conditions, without significant losses in fruit quality.

\section{MATERIALS AND METHODS}

'Sapphire', 'Laetitia' and 'Songold' plums were harvested at the lower end of the commercial maturity spectrum (approximately $2.8 \mathrm{~kg}$ firmness, $7.9 \mathrm{~mm}$ penetrometer tip), and 'Angeleno' in the middle of the harvest maturity spectrum (firmness of $3.5 \mathrm{~kg}$ ) in Wellington, Western Cape in the 2001/2002 and 2002/2003 seasons. All fruit were stored at $-0.5^{\circ} \mathrm{C}$ for four days to simulate a commercial accumulation period, before being randomly assigned to four treatments applied during the simulated shipping phase of fruit destined for export from South Africa:

i) RA under dual temperature (DT) conditions,

ii) $\mathrm{CA}\left(5 \% \mathrm{O}_{2}\right.$ and $\left.10 \% \mathrm{CO}_{2}\right)$ under dual temperature conditions,

iii) RA under a single high temperature (ST) condition of $7.5^{\circ} \mathrm{C}$, and

iv) $\mathrm{CA}\left(5 \% \mathrm{O}_{2}\right.$ and $\left.10 \% \mathrm{CO}_{2}\right)$ under a single high temperature condition of $7.5^{\circ} \mathrm{C}$.

The dual temperature regime consisted of a further 6 days at $-0.5^{\circ} \mathrm{C}$ plus 12 days at $7.5^{\circ} \mathrm{C}$, whereas the single high temperature regime consisted of 18 days at $7.5^{\circ} \mathrm{C}$. After this simulated shipping period, fruit temperature was again lowered to $-0.5^{\circ} \mathrm{C}$ for 14 days ('Sapphire' and 'Laetitia') or 21 days ('Songold' and 'Angeleno') to simulate distribution and storage in the market. Thereafter, fruit were kept for 5 days at $15^{\circ} \mathrm{C}$ to simulate shelflife conditions. Fruit quality was evaluated three times, viz. after simulated shipping, after distribution and after shelf-life. During the simulated shipping phase, CA or RA conditions were imposed using a flow-through system.

The following quality characteristics were determined: firmness (McCormick penetrometer, using an $8 \mathrm{~mm}$ tip on opposite, pared cheeks), soluble solids content (pooled juice from 10 fruit, using an Atago refractometer with automatic temperature compensation), titratable acidity (pooled juice from 10 fruit, using a Metrohm autotitrator and $\mathrm{pH}$ endpoint of 8.2), skin colour (subjectively, on a scale of 0 (green) to 100 (fully coloured) according to the method of Truter and Combrink, 1992; as well as objectively using a Nippon NR3000 colorimeter), weight loss, respiration rate (S151, Kingston, Ontario), ethylene production rate and internal ethylene content (according to the method of Saltveit, 1982, using a Varian Series 3000 gas chromatograph, Palo Alto, California), decay, shrivel (visual rating) and internal defects (using a subjective scoring of the percentage of fruit affected by gel breakdown, internal browning or aerated flesh). 
Each treatment was replicated four times, with ten fruit per replicate and evaluation time. Results were subjected to an analysis of variance (ANOVA) of the main effects and LSD values with a significance level of 5\% were obtained using Statistical Analysis Systems (SAS).

\section{RESULTS AND DISCUSSION}

There were no significant treatment effects on soluble solids content, titratable acidity, weight loss or decay in any cultivar (data not shown). Both 'Laetitia' and

'Sapphire'were free of internal defects (data not shown). In all four plum cultivars, the use of CA conditions during the simulated shipping phase retarded the decrease in flesh firmness during the subsequent storage, regardless of the use of dual temperature or single high temperature shipping regimes. Data were similar for 'Sapphire', 'Songold', and 'Laetitia' and therefore 'Sapphire' data are shown as representative of all three cultivars (Fig. 1). At the first evaluation, following the end of the shipping phase, CA stored 'Sapphire' were significantly firmer than RA stored fruit, and the dual temperature regime maintained firmness better than the single high temperature in the case of the RA treatments.

Flesh firmness of the CA shipped fruit was fairly well maintained during the subsequent 14 days under RA conditions, but by the end of the distribution period only the CA shipped fruit was firmer than the supermarket minimum specification of $1 \mathrm{~kg}$ firmness. During the subsequent five days at $15^{\circ} \mathrm{C}$, CA shipped fruit softened appreciably and were slightly below the $1 \mathrm{~kg}$ minimum level at the end of the shelf life period. In the case of 'Angeleno', CA shipped fruit were also significantly firmer than RA shipped fruit at the end of the simulated shipping period (Fig. 2), although the differences were not as marked as in the case of 'Sapphire'.

By the end of the distribution phase, three weeks later, the fruit shipped under a single high temperature regime and RA conditions was significantly softer than the other three treatments. By the end of the shelf life phase, these fruit were also significantly the softest, being slightly above the supermarket minimum firmness specification of $1 \mathrm{~kg}$. Fruit shipped under a $\mathrm{CA}$ and dual temperature regime was firmer than fruit shipped under RA conditions and a dual temperature regime. Development of skin colour was retarded significantly by CA conditions during shipping for both 'Songold' and 'Sapphire' - hence, 'Sapphire' data are shown as representative of both cultivars (Fig. 3). Skin colour was significantly more advanced in the case of the RA shipped fruit at all three evaluation times.

There was very little change in skin colour during the distribution phase, regardless of the temperature regime or atmospheric conditions during shipping. The greatest change in skin colour occurred in the CA shipped fruit during the 5 day period under shelf life conditions of $15^{\circ} \mathrm{C}$. The temperature regime had no significant effect on this pattern, in either CA or RA shipped fruit. In 'Songold', the CA shipped fruit had very little red colour development by the end of the shelf life period, and fruit were bright yellow in appearance.

The RA shipped fruit, however, had developed significant red pigmentation in the skin, regardless of the temperature regime used during shipping. This difference may be used to manipulate fruit colour to meet specific market demands, as some markets prefer the fruit to have a blush and others not. In the case of 'Laetitia', skin colour development was retarded by the use of the dual temperature shipping regime, in comparison with the single high regime of $7.5^{\circ} \mathrm{C}$ (Fig. 4). 
In the case of the single temperature regime, CA had no effect on further development of skin colour. In the case of the dual temperature shipped fruit, the use of CA tended to retard skin colour development, although the differences with RA were only significant at the end of the distribution phase. All treatments led to a satisfactory skin colour development by the end of the shelf life period.

'Angeleno' skin colour was dark in all treatments, but there were some treatment effects in flesh colour. Fruit shipped under RA conditions had some reddening of the flesh, accentuated in the case of the single high temperature shipping regime. In contrast, the CA shipped fruit had almost no flesh reddening, regardless of the temperature regime used during shipping. 'Songold' fruit had very low levels of internal browning at the end of the shelf life period, with no treatment effects.

However, gel breakdown levels were significantly higher in the case of the fruit shipped under RA conditions under the single high temperature regime (Table 1). This can be ascribed to the fact that these fruit were the ripest, and gel breakdown is associated with higher fruit maturity. There were no differences in gel breakdown levels between the other three treatments. 'Angeleno' had fairly high levels of aerated flesh, especially in the fruit shipped under the dual temperature shipping regime (Table 1). There were no differences between RA and CA shipped fruit, and the temperature regime appeared to have the largest effect on the development of aerated flesh.

The respiration rate of the 'Songold' plums shipped under RA conditions was consistently higher in the case of fruit shipped under the single high temperature regime than those shipped under the dual temperature regime (Fig. 5). During the distribution and shelf life phases, however, these differences were not seen. In the fruit shipped under CA conditions, respiration rates during the distribution phase were very similar, regardless of the temperature regime used during shipping. However, there appeared to be a consistently higher respiration rate in the fruit shipped under the single high temperature regime when measured during the shelf life phase.

During both the distribution and shelf life phases, respiration rates of fruit shipped under CA conditions were consistently lower than those of fruit shipped under RA conditions, regardless of the temperature regimes used during the shipping phase. This suggests that the CA imposed during shipping had an inhibitory effect on fruit respiration lasting for a further three weeks of RA storage plus 5 days at $15^{\circ} \mathrm{C}$.

There was almost no detectable internal ethylene in 'Songold' fruit at the end of the shipping phase when fruit were shipped under CA conditions, regardless of the temperature regime used (Fig. 6). In fact, levels of ethylene were still very low by the end of the distribution phase. 'Songold' shipped under single high temperatures and RA conditions had higher levels of internal ethylene than fruit shipped under RA and dual temperature conditions.

By the end of the shelf life phase the RA shipped fruit had significantly higher levels of internal ethylene than the fruit shipped under CA. In the case of 'Angeleno', the levels of internal ethylene were substantially lower than those of 'Songold', regardless of the shipping conditions or time of evaluation. 'Angeleno' is regarded as a suppressed climacteric plum cultivar, which ripens very slowly. Suppressed climacteric plums produce a fraction of the ethylene and production starts later when compared to climacteric plums, thus they ripen slower (Abdi et al. 1998).

This is supported by the data from this research, and is seen commercially where 'Angeleno' has a reputation for a very long storage life in comparison to most other Japanese plum cultivars. There were only small differences in internal ethylene content between treatments following the shipping phase, but by the end of the distribution phase the fruit shipped under RA conditions had significantly higher internal ethylene levels than fruit shipped under CA. The single temperature shipping conditions tended to cause higher internal ethylene levels, especially in RA shipped fruit. 


\section{CONCLUSIONS}

This research has demonstrated that significant benefits can be accrued through use of controlled atmosphere during the shipping phase for four commercial plum cultivars grown in South Africa. The primary benefit is retention of fruit firmness for a period of two to three weeks under regular atmosphere storage following the controlled atmosphere conditions. On a physiological level the controlled atmosphere retards the accumulation of internal ethylene as well as fruit respiration rate, with both processes benefiting from a carryover effect following the cessation of controlled atmosphere.

\section{ACKNOWLEDGEMENTS}

Transfresh Africa for funding the postgraduate studies of Leon Maré and for establishing the CA facility in the Department of Horticultural Sciences, University of Stellenbosch. Sandrivier Estate, Wellington for supplying the fruit used in the trials.

\section{Literature Cited}

Abdi, N., McGlasson, W.B., Holford, P., Williams, M. and Mizrahi, Y. 1998. Responses of climacteric and suppressed-climacteric plums to treatment with propylene and 1methylcyclopropene. Postharvest Biol. Technol. 14: 29-39.

Anonymous. 2003. Key deciduous fruit statistics 2003. Deciduous Fruit Producers' Trust, Paarl, South Africa.

Saltveit, E.M. Jr. 1982. Procedures for extracting and analyzing internal gas samples from plant tissues by gas chromatography. HortScience 17: 878-881.

Taylor, M.A. 1996. Internal disorders in South African plums. Decid. Fruit Grower September: $328-335$.

Truter, A.B. and Combrink, J.C. 1992. Controlled atmosphere storage of peaches, nectarines and plums. J. S. Afr. Soc. Hort. Sci. 2: 10-13. 


\section{Tables}

Table 1. Effect of controlled atmosphere (CA) or regular atmosphere (RA) under a dual temperature (DT) or single high temperature (ST) shipping regime on internal browning (IB) and gel breakdown (GB) of 'Songold' and aerated flesh of 'Angeleno'plums'.

\begin{tabular}{cccc}
\hline Treatment & Songold \% IB & Songold \% GB & Angeleno \% aerated flesh \\
\hline CA DT & $2.8 \mathrm{a}$ & $11.1 \mathrm{~b}$ & $25.7 \mathrm{a}$ \\
CA ST & $0.0 \mathrm{a}$ & $13.9 \mathrm{~b}$ & $11.1 \mathrm{~b}$ \\
RA DT & $0.0 \mathrm{a}$ & $17.0 \mathrm{~b}$ & $19.4 \mathrm{ab}$ \\
RA ST & $3.1 \mathrm{a}$ & $44.4 \mathrm{a}$ & $5.6 \mathrm{~b}$ \\
\hline
\end{tabular}

${ }^{\mathrm{z}}$ Values within columns followed by the same letter do not differ significantly at $\mathrm{P}<0.05$. 


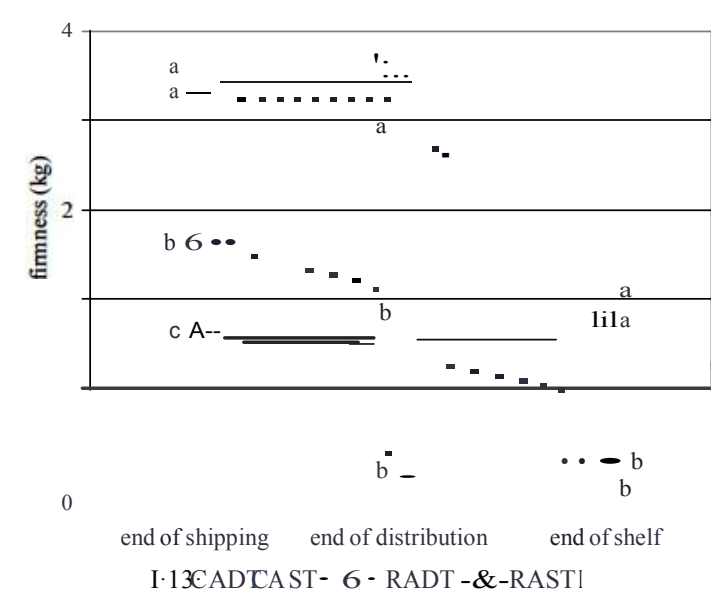

Fig. 1. Effect of controlled atmosphere (CA) or regular atmosphere (RA) under a dual temperature (DT) or single high temperature (ST) shipping regime on firmness of 'Sapphire' plums. Within evaluation times, values followed by the same letter do not differ significantly at $\mathrm{P}<0.05$.

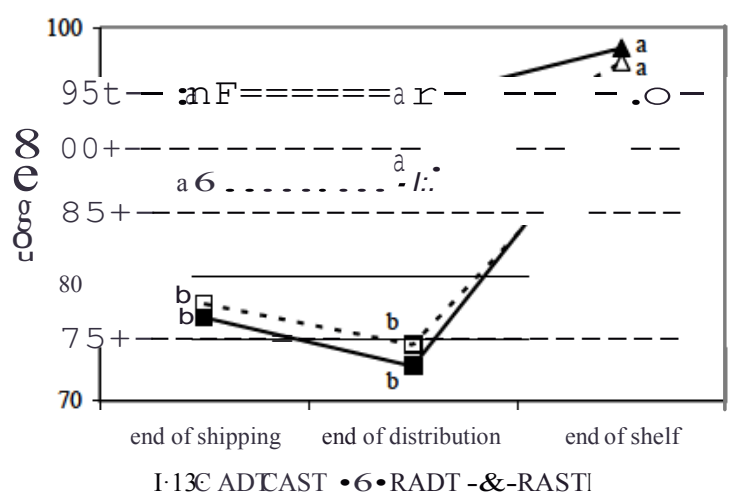

Fig. 3. Effect of controlled atmosphere (CA) or regular atmosphere (RA) under a dual temperature (DT) or single high temperature (ST) shipping regime on skin colour of 'Sapphire' plums. $0=$ green, $100=$ fully coloured. Within evaluation times, values followed by the same letter do not differ significantly at $\mathrm{P}<0.05$.

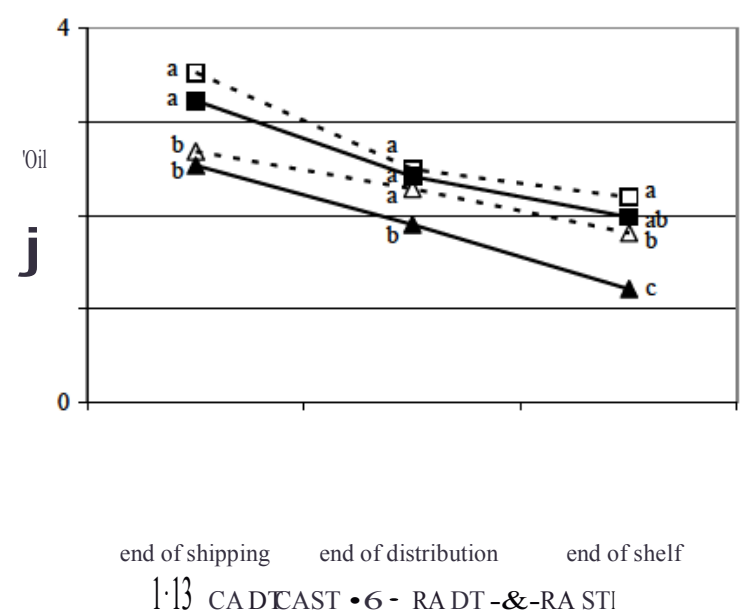

Fig. 2. Effect of controlled atmosphere (CA) or regular atmosphere (RA) lmder a dual temperature (DT) or single high temperature (ST) shipping regime on finnness of 'Angeleno' plums. Within evaluation times, values followed by the same letter do not differ significantly at $\mathrm{P}<0.05$.

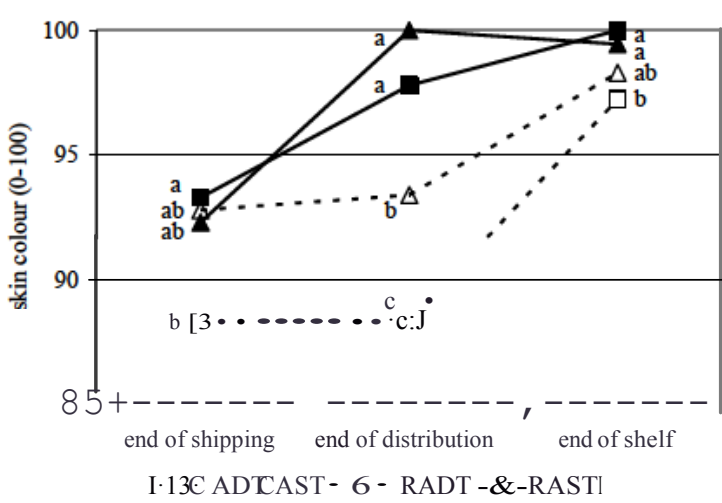

Fig. 4. Effect of controlled atmosphere (CA) or regular atmosphere (RA) under a dual temperature (DT) or single high temperature (ST) shipping regime on skin colour of 'Laetitia' plums. $0=$ green, $100=$ fully coloured. Within evaluation times, values followed by the same letter do not differ significantly at $\mathrm{P}<0.05$. 


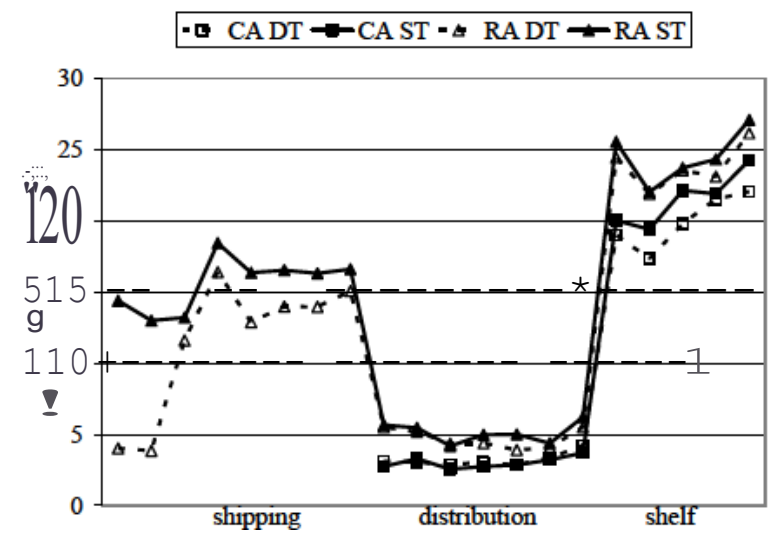

Fig. 5. Effect of conu olled atmosphere (CA) or regular atmosphere (RA) under a dual temperature (DT) or single high temperature (ST) shipping regime on respiration rate of 'Songold'plums.
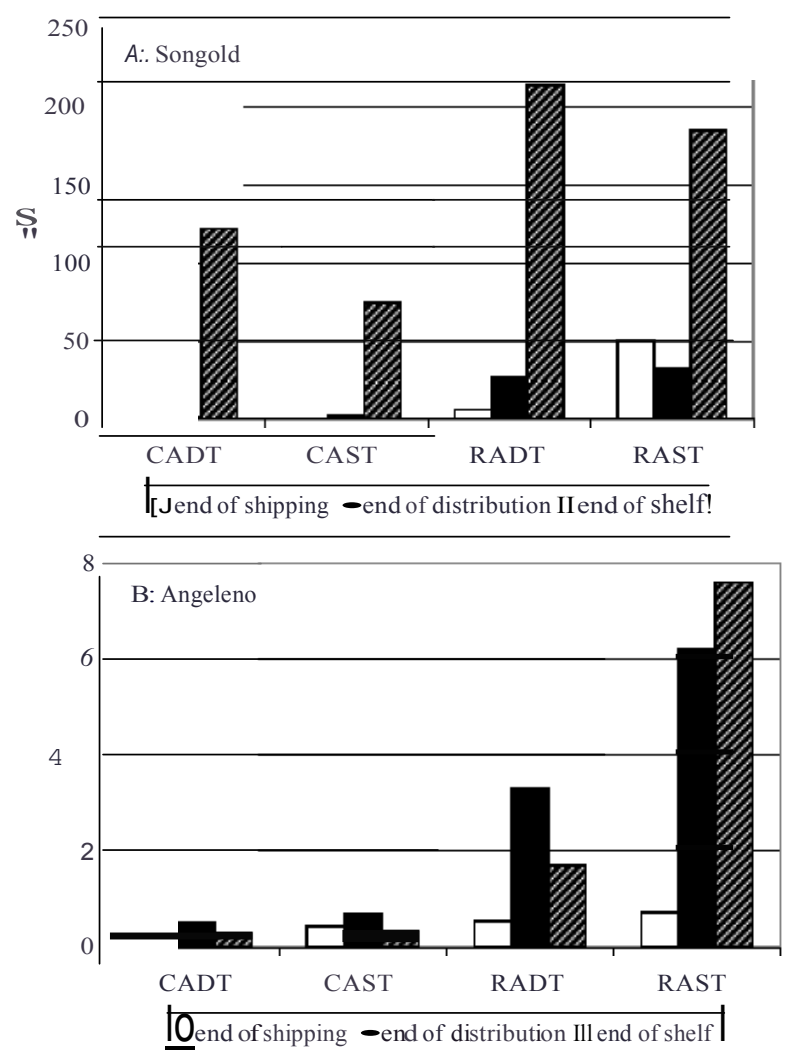

Fig. 6. Effect of conu olled atmosphere (CA) or regular ahnosphere (RA) under a dual temperature (DT) or single high temperature (ST) shipping regime on intemal ethylene content of of A: 'Songold' and B: 'Angeleno'plums. 